\title{
Development of the Modern Financial Management
}

\author{
Jingxi Gu \\ Economics and Management Engineering, Chengdu College of University of Electronic Science and \\ Technology of China, Chengdu 611731, China
}

574037875@qq.com

Keywords: Big data, Internet, Financial Management.

\begin{abstract}
With the emergence of big data and the arrival of information era, along with the continuous development of Internet technology, working mode and working methods of financial management have a broad space for further development. The development of enterprises can be prompted by the realization of financial data informatization, financial services sharing, financial payment facilitation, financial terminal mobility and other means, yet it will also result in the situation when confidential is easily to be stolen and lacking of relevant professional personnel.
\end{abstract}

\section{Introduction}

\subsection{Big Data}

There are two views on the big data that can interpret its essence. An article from Gartner's Merv Adrian in the first quarter of year 2011, pointed out that "data is beyond the ability of common hardware environment and software tools in an acceptable time to collect, manage and process for its users "[1]. Another report, "Big Data: Next Frontier in Innovation, Competition and Productivity", from the McKinsey Global Research Institute in June 2011 demonstrates that "big data is the dataset whose size is beyond the capabilities of typical database software tools for data collection, storage, management and analysis"[2]. Big data let people obtain the services and products of great value in an unprecedented way by analyzing the massive data. It can be the deep insight for people to see the future, and ultimately become the power of change. Ma Ben and Mao Qingduo [3] proposed that "the application of big data will help improve the efficiency of emergency management, save costs and reduce losses. China needs to explore and figure out more forms of application of big data in big data strategy, big data open policy, and the use of big data in the emergency management. " Zhang Dongxia, Miao Xin, Liu Liping, Zhang Yan, Liu Yanke [4] proposed that "smart grid produced a lot of data, the application of big data technology can effectively improve the level of grid operation and management, as well as the service level for the society and users. " Liu Yong Qian and Yang Xianmin [5] proposed the idea of balanced development of regional education in the big data era. Under the age of big data, regional education should be based on the development of data. People should accurately grasp the trends of regional education development by using big data technology from the perspectives of balanced educational environment, balanced education resources, equal access to education and balanced education quality in in order to prompt the balanced development of regional education.

\subsection{Internet+}

With the development of social information, "Internet + " received an unprecedented attention from all fields while its connotation has been also defined in several ways. In 2015, chairman and the Chief Executive Officer of Tencent Huateng Ma pointed out in "the proposal on Internet+ as the driving force to promote the development and innovation of China's economic society" that 'Internet + ' is based on the Internet platform which, with the combination of the use of information and communication technology and cross-border integration of various industries, can promote industrial transformation and upgrading, and continue to create new products, new business and new models, in order to build a new ecological connection, and to vigorously promote the 
development of China's economy and society. "[6] Founder, chairman, and Chief Executive Officer of Baidu Yanhong Li expressed his opinion that 'Internet +' plan is a combination of the Internet and other traditional industries model. In recent years, with the number of Internet users in China increased, the penetration rate is close to $50 \%$, especially the rise of mobile Internet that makes the Internet produce more and more influence in other industries. "[7] Professor Huang Huang from Peking University thinks that " 'Internet +' not only includes manufacturing, but also includes ecommerce, industrial Internet, Internet finance and innovation. 'Internet + ' is an upgraded version of the integration of two, which is not a pure industrialization, but the core of the current information technology, and to be combined with the industrial, commercial, financial and other services. "[8] Sina Chief Executive Officer and Chairman Cao Guowei emphasized when attending the" China Development Forum" that " 'Internet + ' represents a new economic form, which integrates the Internet and the traditional industry in-depth and creates the new ecology of development. "[9] Entrepreneurs and scholars have explored the connotation of Internet + from various aspects and they have pointed out that" Internet + "is not just infrastructure, but also the integration to rebuild our thinking mode and will become the new ecology of our life.

\subsection{Financial Management}

Financial management is arisen based on the objective existence of the financial activities and financial relations during the reproduction of enterprise, which is an economic management work to organize financial activities, and to deal with all aspects of financial relations.

The traditional financial management is a simple, passive, lagging financial management model. With the development of the socialist market economy, according to the inherent nature and requirements of modern enterprises, the establishment of modern enterprise financial management model is the inevitable requirement to develop socialized large-scale production and market economy in accordance with international practice and standards.

Modern enterprise system has the characters of clear property rights, clear rights and responsibilities, separation of government and enterprises, and scientific management. Organizational form is diversified, collectivized management, and increasingly presents large-scale, transnational, cross-industry business trends. The above characteristics of modern enterprises put forward new requirements for the current accounting management mode of Chinese enterprises.

Financial management is directly related to the survival and development of enterprises, to some extend, financial management is a key to sustainable development of enterprises. The big data, the Internet play a crucial role for the further development of modern financial management.

\section{Changes and impacts of Financial Management}

In the information age, Internet technology continues to be improved and upgraded. After the cloud computing, and the Internet of Things, the impact brought by development and application of data can not be underestimated. The new technology in the Internet age has changed the mode and application of traditional enterprise financial management. As a new technology product, big data has opened up a new world for enterprise financial management, and financial management becomes more efficient under their mutual action. Wang Ziqi [10] states that the existed level of traditional financial management network is low, with poor integration of resources, high cost of labor costs, whose senior personnel are not enough, whose financial decision-makings are unreasonable, and whose quality is relatively low. The era of big data is conducive to the efficient and accurate management of financial information, corporate decision-making and risk aversion, which can promote the improvement of corporate financial quality as well as the corporate financial innovation.

Ming Ke and Yuxin Shi believe that through fully processing accounting data and mining financial information fully, the enterprise can improve its financial management, lower cost of capital, and make higher profit [11]. Han Xue presented that in the era of information, a profound impact on the progress and development of the production, supply, transportation, cost control, sales management and other aspects, means of information and computer technology is changing 
the traditional enterprise operation and management mode. Through the application of information technology, the company's financial management can be at a greater degree of progress and development, promoting the upgrading of the level of financial management, enabling enterprises to achieve as soon as possible and improving the internal management optimization in order to have a stronger market competitiveness and to ensure economic efficiency of enterprises. [12].

Huang Wenxia states that financial management information is a revolution of the development of financial management in information society, which is a symbol of financial analysis developing to the right direction. Informatization has brought significant changes and influence on the enterprise financial management and supply chain management, so that the competitiveness of enterprises has been greatly improved and will also help improve the efficiency of enterprise financial management, hence to help enterprises to adapt to the development of market economy, and to optimize the enterprise resources, as a result, to improve the core competitiveness of enterprises.

It also has the information function for financial risk predicting, and monitoring. The establishment of financial risk information system can play a protective role for strengthening the enterprise risk management, and improving the mutual communication among internal departments and among external enterprises [13].

Big data and the Internet still lead to some problems and challenges. Ming Ke and Yuxin Shi clarified that if the workers gather all the data in spite of quality, it would be possible to make wrong predictions and decisions. And it will be much easier to leak the privacy. What's more, big data application requires enterprise to design new data analysis models. That is because traditional models are fit to process structured data rather than big data, including multi-type data. [11]. Kang $\mathrm{Y}$ thinks that since network is open, it is easy to be stolen in the process of information transmission, test and interception, which has brought great security risk to the enterprise financial management. And it is a challenge that the Internet has changed the trading patterns and financial management models, making raw material procurement, product sales, consignment and a series of procedures to be completed online. These changes require the financial management of the enterprise to change accordingly, which can handle a variety of electronic documents, electronic money, pages data [14]. Jun-Ya Cheng and Pei-Wu Dong believed that there is a certain degree of technical difficulty for big data transfer, storage and analysis, while corporation data management is lagging behind, thus it is not able to timely analyze data and offer support for decision making [15].

\section{Conclusion and expectations}

Through the adequate analysis of scholars on the financial management work in the field of Internet, big data, and information age background, it is clear to see that except for pursuing the economic and social development, enterprises, in order to dominate in the fierce market, have to do well in financial management and to select targeted improvement measures. Enterprises have to be fully aware of the advantages and risks of financial management under the Internet and big data, for instance, corporate financial sharing platform, mobile phone APP and others need staff to login and enter the password, and these accounts and password security is low, which is easy to be stolen by some criminals (such as hackers or criminal groups, etc.). They also have the potential to invade the manager's account to steal the company's financial information and leak the information by selling them to others. In addition, the mobile Internet changes the previous contracts, documents, handwritten signatures into electronic ones, which are difficult to be identified its authenticity. This gives others permission to mock the signatures and to bring transaction risks to corporates.

Financial management is not a mechanical, single system, but a dynamic development process, where the financial control system will change accordingly with the changes of enterprise management environment. Therefore, enterprises need to be able to strengthen the use of network information technology on the basis of traditional financial management methods, and to do a good job of financial control and innovation with the combination of business process requirements, in order to meet the requirements of sustainable development and to create greater economic and social benefits. 
In the coming future, in order to further improve the level of data analysis of financial management, we must give full play to the advantages of traditional financial management, as well as choosing the correct management methods and management tools to enhance the financial management subjective initiative. With the full use of big data and the Internet + , people should also take human resources advantages, so as to take into account the efficiency of financial management at the same time to ensure that human resources can also be fully utilized.

After the establishment of the interconnection of financial control system, following design principles have to be fully complied. Financial control process does not put the system security in a prominent position. With the combination of accounting system related requirements, in the financial reporting system and control process, financial activities and economic activities have mutual restraint, which enables financial departments to contain and balance with each other, fundamentally reduce the financial management arrogant or authoritarian, to ensure that the company's financial management can provide more information and data guidance for the enterprise development.

\section{References}

[1] Merv Adrian. Big Data: it's going mainstream and it's your next opportunity [J]. Teradata Magazine, 2011, (1): 3-5.

[2] Manyika J, ChuiM, Brown B, et al. Big data: The next frontier for innovation, competition, and productivity[R].USA: Mckinsey Global Institute, 2011.

[3] Ma Ben, Mao Qingduo. Application of large data in emergency management, 2015 (03).

[4] Zhang Dongxia, Miao Xin, Liu Liping, Zhang Yan, Liu Yanke. Research on Development of Large Data Technology for Smart Grid, Journal of China Society for Electrical Engineering, 2015 (01).

[5] Liu Yongqian, Yang Xianmin.New data age regional education balanced development of new ideas, audio-visual education research, 2014 (05).

[6] Ma Teng. On the "Internet +" to promote China's economic and social innovation and development of the proposed [J]. China Science and Technology Industry, 2016, (3): 38-39.

[7] Li Yanhong talk about the Internet and the combination of traditional enterprises: the decay of the magic [EB / OL]. 2015-08-19 / 2016-07-22.http: //www.chinanews.com/gn/2015/03-11 /7118892.shtml.

[8] Jiang Qi-ping, Zhou Qiren, Chen Zhiwu, etc. Read the "Internet +" [M]? Beijing: CITIC Press, 2015: 28, 28, V.

[9] Cao Guowei. "Internet +" represents a new economic form [EB / OL]. 2015-03-21 / 2016-0722.http: //tech.sina.com.cn/i/2015 -03-21 / 163710019803.shtml

[10]Wang Zilin. large data age under the financial management [J]. "Economic Research Guide" 2016(23):116-117.

[11] Ke M, Shi Y. Big Data, Big Change: In the Financial Management [J]. Open Journal of Accounting, 2014, 03(4):77-82.

[12] Han Xue. dynamic financial management model under the information age [J]. Accounting learning, 2015, 18: 91.

[13] HUANG Wen-xia.Study on the Development of Information-based Financial Management [J]. Finance \& Accounting, 2011 (18): 114-115.

[14] Kang Y. Research on the Innovation of Enterprise Financial Management Based on the Internet[C]// International Conference on Economy, Management and Education Technology. 2016. 
[15] Cheng J Y, Dong P W. Thinking of Corporation Financial Management Innovation in the Era of Big Data [J]. 2015. 